\title{
A Rare Emergency: Testicular Torsion in the Inguinal Canal
}

\author{
Nevzat Can Şener, ${ }^{1}$ Okan Bas, ${ }^{2}$ Nihat Karakoyunlu, ${ }^{3}$ Hakan Ercil, ${ }^{1}$ Suleyman Yesil, ${ }^{4}$ \\ Kursad Zengin, ${ }^{5}$ and Abdurrahim Imamoglu ${ }^{3}$ \\ ${ }^{1}$ Department of Urology, Numune Teaching and Research Hospital, Ministry of Health, Adana, Turkey \\ ${ }^{2}$ Department of Urology, Abdurrahman Yurtarslan Onkoloji Teaching and Research Hospital, Ankara, Turkey \\ ${ }^{3}$ Department of Urology, Diskapi Yildirim Beyazit Teaching and Research Hospital, Ministry of Health, Ankara, Turkey \\ ${ }^{4}$ Department of Urology, Gazi University School of Medicine, Ankara, Turkey \\ ${ }^{5}$ Department of Urology, Bozok University School of Medicine, Yozgat, Turkey
}

Correspondence should be addressed to Nevzat Can Şener; cansener14@gmail.com

Received 10 August 2014; Revised 10 October 2014; Accepted 12 October 2014

Academic Editor: Seiichi Saito

Copyright (C) 2015 Nevzat Can Şener et al. This is an open access article distributed under the Creative Commons Attribution License, which permits unrestricted use, distribution, and reproduction in any medium, provided the original work is properly cited.

Objectives. To report our experience and present the largest series of testicular torsion cases in the inguinal canal. Material and Methods. The clinical data of 13 patients with testicular torsion in the inguinal canal treated between 2005 and 2013 were reviewed. Recorded patient age, whether the testes were palpable or not, side of the affected testes, the presence of hernia, ischemia time, and operation outcomes were assessed. Results. Patient age ranged from 8 to 70 months $(29.15 \pm 20.22)$. Mean ischemia time was $16.5 \pm 21.3$ hours. Accompanying inguinal hernia was present in $92 \%$ of the cases $(12 / 13)$. Four of the thirteen patients $(30.8 \%)$ were treated by orchiectomy because the necrosis was present after prolonged ischemia time. Nine patients (69.2\%) were treated by single session orchidopexy. Conclusion. Torsion of testes in the inguinal canal is a rare disease, but with rapid diagnosis, affected testes can be salvaged, but the key factor is to keep this condition in mind.

\section{Introduction}

Testicular torsion is a urologic emergency that needs immediate attention and treatment. The rotation of the spermatic cord leads to venous and arterial flow compromise, which results in ischemia in about 6-24 hours [1].

Undescended testis, or cryptorchidism, is usually present at birth. About $1 / 3$ premature male newborns have this condition [2]. One percent of term male infants suffer from cryptorchidism [2]. It is the most common congenital anomaly affecting genitalia of newborn male infants [3].

The most common symptom of testicular torsion is scrotal pain. However, when testes are undescended, like testicular torsion in the inguinal canal, the diagnosis becomes harder for the physician. The incidence of torsion of cryptorchidism is thought to be higher than torsion of the scrotal testes [4]. However, there are limited data on testicular torsion in the inguinal canal. In this paper, we aimed to report our experience and present the largest series of testicular torsion cases in the inguinal canal.

\section{Patients and Methods}

Between 2005 and 2013, 217 patients were treated in our clinic for testicular torsion. Of these patients, 13 had testicular torsion in the inguinal canal. The clinical data of these patients were reviewed. Age at presentation, associated anomalies, and operation outcomes were studied.

Diagnosis of testicular torsion was confirmed by physical examination and scrotal Doppler ultrasound (SDU).

Recorded patient age, whether the testes were palpable or not, side of the affected testes, the presence of hernia and ischemia time, and operation outcomes were assessed.

Statistical analyses were performed using Statistical Package for Social Sciences (SPSS) 20 software for MAC (SPSS 
TABLE 1: Characteristics and outcomes of patients.

\begin{tabular}{lcccccc}
\hline Patient & $\begin{array}{c}\text { Age } \\
\text { (months) }\end{array}$ & Side & $\begin{array}{c}\text { Symptom } \\
\text { duration (hours) }\end{array}$ & Necrosis? & $\begin{array}{c}\text { Torsion } \\
\text { degree }\end{array}$ & Outcome \\
\hline 1 & 16 & Right & 7 & No & 270 & Orchidopexy \\
2 & 22 & Left & 8 & No & 180 & Orchidopexy \\
3 & 15 & Left & 11 & Yes & 360 & Orchidectomy \\
4 & 24 & Left & 26 & Yes & 360 & Orchidectomy \\
5 & 18 & Left & 22 & Yes & 180 & Orchidectomy \\
6 & 70 & Left & 84 & Yes & 270 & Orchidectomy \\
7 & 16 & Left & 8 & No & 270 & Orchidopexy \\
8 & 8 & Right & 4 & No & 270 & Orchidopexy \\
9 & 23 & Right & 11 & No & 270 & Orchidopexy \\
10 & 22 & Right & 10 & No & 180 & Orchidopexy \\
11 & 56 & Left & 4 & No & 360 & Orchidopexy \\
12 & 64 & Right & 8 & No & 270 & Orchidopexy \\
13 & 25 & Left & 12 & No & 180 & Orchidopexy \\
\hline
\end{tabular}

Inc., Chicago, IL, USA). All the data are presented as mean (range).

\section{Results}

Clinical presentations consisted of irritability, persistent crying, swelling, and pain in the inguinal region. Age of the patients ranged from 8 to 70 months $(29.15 \pm 20.22)$. All the testes were palpable in the inguinal region. The affected testes were $38.5 \%$ right and $61.5 \%$ left.

The mean ischemia time was $16.5 \pm 21.3$ hours. Accompanying inguinal hernia, which was detected intraoperatively, was present in $92 \%$ of the cases (12/13). Hernia repair was performed on these patients.

Four of the thirteen patients $(30.8 \%)$ were treated by orchiectomy because the necrosis was present after prolonged ischemia time. Nine patients $(69.2 \%)$ were treated by single session orchidopexy.

Patients were followed up for a mean of 23.7 months. From nine patients treated by orchidopexy, two patients suffered from testicular atrophy at a mean of 11.5 months.

Patient characteristics and operative outcomes were summarized in Table 1.

\section{Discussion}

Testicular torsion is a real urologic emergency. Sudden diagnosis and intervention should be made because it may result in the loss of the testicle. With immediate recognition and management, 40 to $60 \%$ of testicles can be salvaged $[5,6]$. Davenport proposed a salvage rate of $90 \%$ with the diagnosis of testicular torsion in six hours after the incident, whereas the salvage rate decreases to less than $10 \%$ after 24 hours [1].

Cryptorchid or undescended testis is classified as abdominal, inguinal, or subinguinal. About $75 \%$ of undescended testis is classified as inguinal [7]. Cryptorchidism may cause lower sperm count, worsened sperm quality, and lower fertility rates. These conditions are worse when undescended testis is bilateral and orchidopexy is performed at an older age [8]. Gaudio et al. demonstrated the decrease of germ cell density in cryptorchidism after 1 year of age [9].

There is a significantly higher risk of testicular tumors in patients with undescended testis among normal population (1/1000-2500 to $1 / 100,000)$ [10]. Management with orchidopexy has not been proven for risk reduction but detection by self-examination is eased with orchidopexy [11].

Cryptorchid testis is more prone to torsion, compared to normal testicle. There are articles proposing 10 times higher risk of torsion in cryptorchid testicle $[12,13]$. Even though it is more frequent, the literature of torsion of undescended testicle is mostly limited to case reports $[14,15]$. The reports propose a rapid intervention and mostly focus on diagnostics. Erdogan et al. report a case with inguinal hernia, where sudden onset of symptoms gave rise to suspicions of testicular torsion, even with complicated presentation [16].

As important as duration, degree of cord twisting is a critical factor for the outcome of testicular torsion [17]. When twisting is $>360$ degrees, torsion as short as 4 hours may facilitate testicular atrophy. If the torsion is not complete (<360 degrees), testicles with torsion within 24 hours may be salvaged [18]. With the presence of complete torsion (360 degrees), severe testicular atrophy was reported. However, with incomplete torsion ( $<360$ degrees), atrophy was not observed even within 12 hours [18].

For differential diagnosis, the most important factor is physician's experience. One must always keep the undescended testicle in mind when an inguinal mass and tenderness are present. However, testicular torsion may not always be the case. Orchitis of undescended testicle, incarcerated inguinal hernia, and tumor of the undescended testicle should be kept in mind. Scrotal Doppler ultrasonography usually helps supporting the diagnosis [19-21].

In this report, 13 patients with testicular torsion in the inguinal canal and torsion were treated. To our knowledge, this is the largest series concerning testicular torsion in the inguinal canal. The mean patient age was $29.15 \pm 20.21$ 
months. The ages of patients were higher than the age where they should be treated. This is because the majority of our patients were from the countryside and healthcare could not be provided optimally for those who live in countryside in our country. All testes were in the inguinal canal and were palpable. Because the physician can palpate the affected testicle, testicular torsion in the inguinal canal is easier to diagnose among other cryptorchid cases. For example, intraabdominal testis cannot be palpated like other testicular problems but should be kept in mind with the presence of abdominal pain and a missing testicle. It is reported to be a rare cause of acute abdomen [13]. Inguinal hernia is mostly associated with testicular torsion in the inguinal canal [22], and, in our report, this ratio is $92 \%$, similar to those in literature. The mean ischemia time was $16.54 \pm 21.25$ hours. However, we had one case with a history of 84 hours. If this case is neglected, the average is $10.07 \pm 7.06$ hours, which is compatible with the literature. We could be able to salvage $69.2 \%$ of the affected testes. In $30.8 \%$ of the cases, affected testes had to be removed. Torsion angle of the testicle is an important factor for treatment outcomes. One patient in our series with a complete torsion was successfully operated on in 4 hours with the testicle salvaged. However, in another patient with an onset of 11 hours with complete torsion, the operation resulted in orchiectomy.

Even though this study lacks long-term follow-up and has a retrospective method with a very small number of patients, we believe it may yield important information because of the lacking data in current literature and aid physicians to diagnose this infrequent disease.

\section{Conclusion}

Torsion of cryptorchidism is a rare disease, but, with rapid diagnosis, affected testes can be salvaged. Physical examination is the key to diagnosis. Physicians should suspect testicular torsion in the inguinal canal with a missing testis and a tender mass in the ipsilateral inguinal region.

\section{Conflict of Interests}

The authors declare no competing financial interests.

\section{References}

[1] M. Davenport, "ABC of general surgery in children: acute problems of the scrotum," The British Medical Journal, vol. 312, no. 7028, pp. 435-437, 1996.

[2] H. A. Kadish and R. G. Bolte, "A retrospective review of pediatric patients with epididymitis, testicular torsion, and torsion of testicular appendages," Pediatrics, vol.102, no. 1, part 1, pp. 73-76, 1998.

[3] S. Tekgül, H. Riedmiller, H. Dogan et al., Guidelines on Paediatric Urology, 2013.

[4] N. A. Watkin, N. A. Reiger, and C. U. Moisey, "Is the conservative management of the acute scrotum justified on clinical grounds?" British Journal of Urology, vol. 78, no. 4, pp. 623-627, 1996.
[5] F. Hajji and A. Janane, "Images in clinical medicine. Torsion of undescended testis," The New England Journal of Medicine, vol. 366, no. 17, p. 1625, 2012.

[6] F. J. Candocia and K. Sack-Solomon, "An infant with testicular torsion in the inguinal canal," Pediatric Radiology, vol. 33, no. 10, pp. 722-724, 2003.

[7] J. S. Elder, "Cryptorchidism: isolated and associated with other genitourinary defects," Pediatric Clinics of North America, vol. 34, no. 4, pp. 1033-1053, 1987.

[8] S. J. Kogan, "Fertility in cryptorchidism. An overview in 1987," European Journal of Pediatrics, vol. 146, supplement 2, pp. S21S24, 1987.

[9] E. Gaudio, D. Paggiarino, and F. Carpino, "Structural and ultrastructural modifications of cryptorchid human testes," The Journal of Urology, vol. 131, no. 2, pp. 292-296, 1984.

[10] D. Pinczowski, J. K. McLaughlin, G. Läckgren, H.-O. Adami, and I. Persson, "Occurrence of testicular cancer in patients operated on for cryptorchidism and inguinal hernia," Journal of Urology, vol. 146, no. 5, pp. 1291-1294, 1991.

[11] A. J. Swerdlow, C. D. Higgins, and M. C. Pike, "Risk of testicular cancer in cohort of boys with cryptorchidism," The British Medical Journal, vol. 314, no. 7093, pp. 1507-1511, 1997.

[12] D. Zilberman, Y. Inbar, Z. Heyman et al., "Torsion of the cryptorchid testis-can it be salvaged?" The Journal of Urology, vol. 175, no. 6, pp. 2287-2289, 2006.

[13] A. S. Memon and F. G. Siddiqui, "Cryptorchid testicular tumour presenting with torsion," Journal of the College of Physicians and Surgeons-Pakistan, vol. 13, no. 2, pp. 118-119, 2003.

[14] Y. M. Sheref, M. H. Johnson, E. J. Traxel, and G. Khanna, "Case report: torsion of a cryptorchid testicle in an infant," Emergency Radiology, vol. 18, no. 6, pp. 487-489, 2011.

[15] C. P. Moore, J. K. Marr, and C. J. Huang, "Cryptorchid testicular torsion," Pediatric Emergency Care, vol. 27, no. 2, pp. 121-123, 2011.

[16] A. Erdoğan, E. C. Günay, G. Gündoğdu, and D. Avlan, “Testicular torsion in the left inguinal canal in a patient with inguinal hernia: a difficult case to diagnose," Molecular Imaging and Radionuclide Therapy, vol. 20, no. 3, pp. 108-110, 2011.

[17] A. J. Visser and C. F. Heyns, "Testicular function after torsion of the spermatic cord," BJU International, vol. 92, no. 3, pp. 200203, 2003.

[18] G. Tryfonas, A. Violaki, G. Tsikopoulos et al., "Late postoperative results in males treated for testicular torsion during childhood," Journal of Pediatric Surgery, vol. 29, no. 4, pp. 553556, 1994.

[19] L. A. Baker, D. Sigman, R. I. Mathews, J. Benson, and S. G. Docimo, "An analysis of clinical outcomes using color Doppler testicular ultrasound for testicular torsion," Pediatrics, vol. 105, no. 3, part 1, pp. 604-607, 2000.

[20] N. Kalfa, C. Veyrac, M. Lopez et al., "Multicenter assessment of ultrasound of the spermatic cord in children with acute scrotum," The Journal of Urology, vol. 177, no. 1, pp. 297-301, 2007.

[21] P. Pepe, P. Panella, M. Pennisi, and F. Aragona, "Does color Doppler sonography improve the clinical assessment of patients with acute scrotum?" European Journal of Radiology, vol. 60, no. 1, pp. 120-124, 2006.

[22] H. E. Virtanen and J. Toppari, "Epidemiology and pathogenesis of cryptorchidism," Human Reproduction Update, vol. 14, no. 1, pp. $49-58,2008$. 


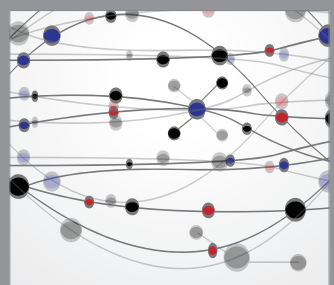

The Scientific World Journal
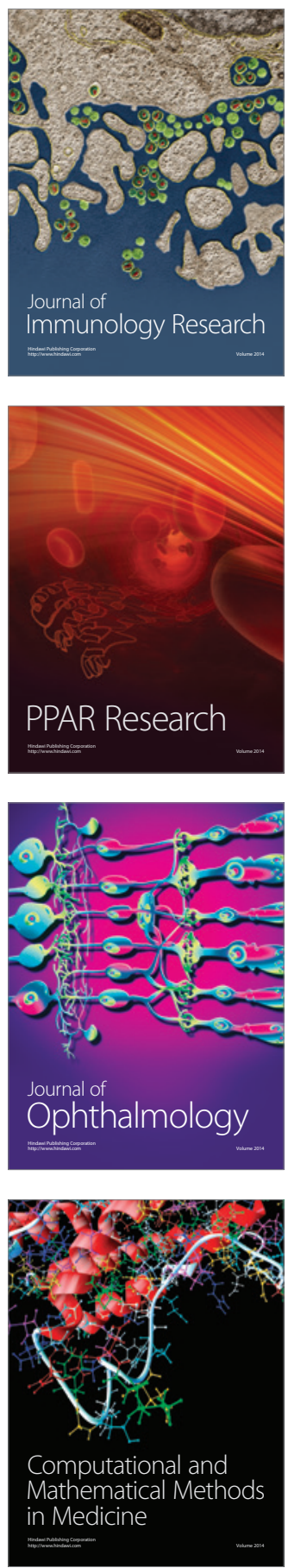

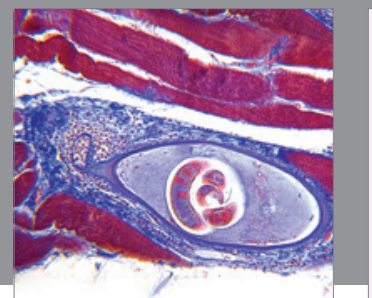

Gastroenterology

Research and Practice
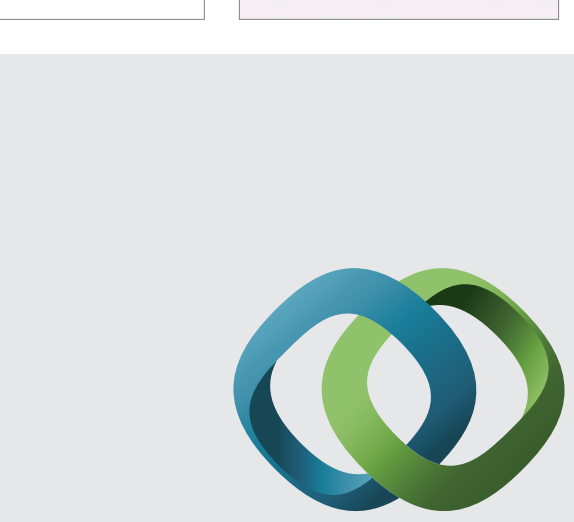

\section{Hindawi}

Submit your manuscripts at

http://www.hindawi.com
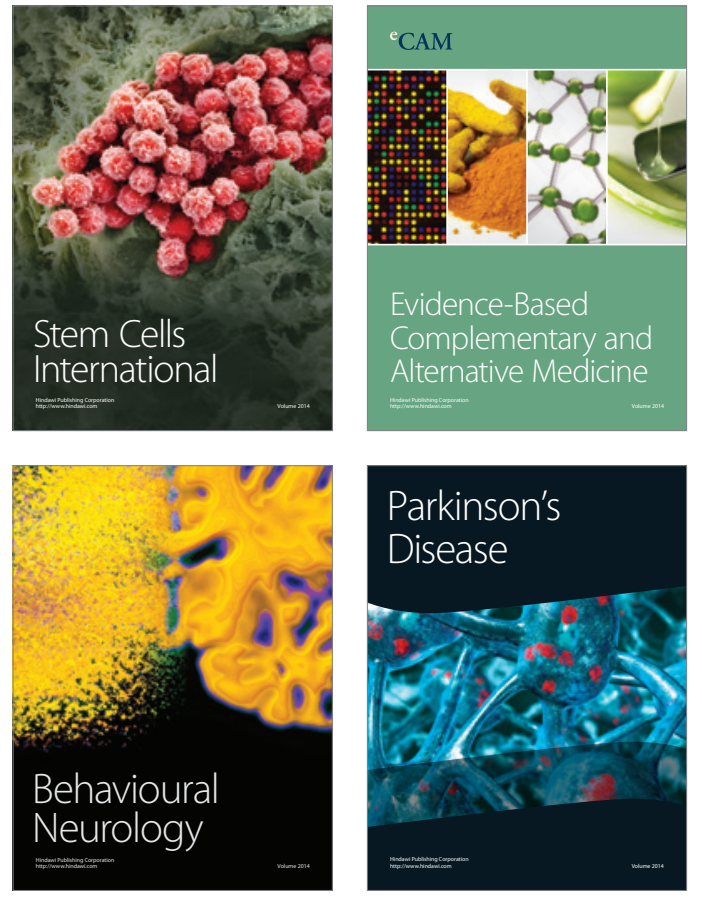
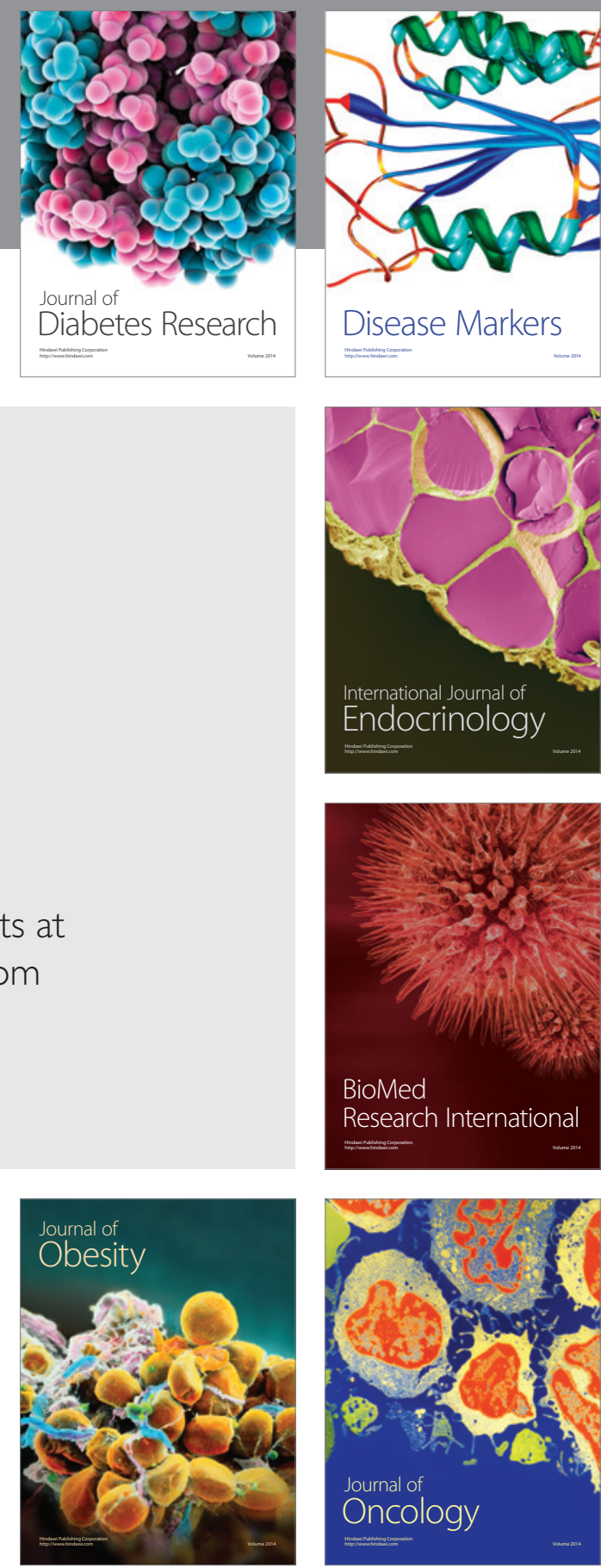

Disease Markers
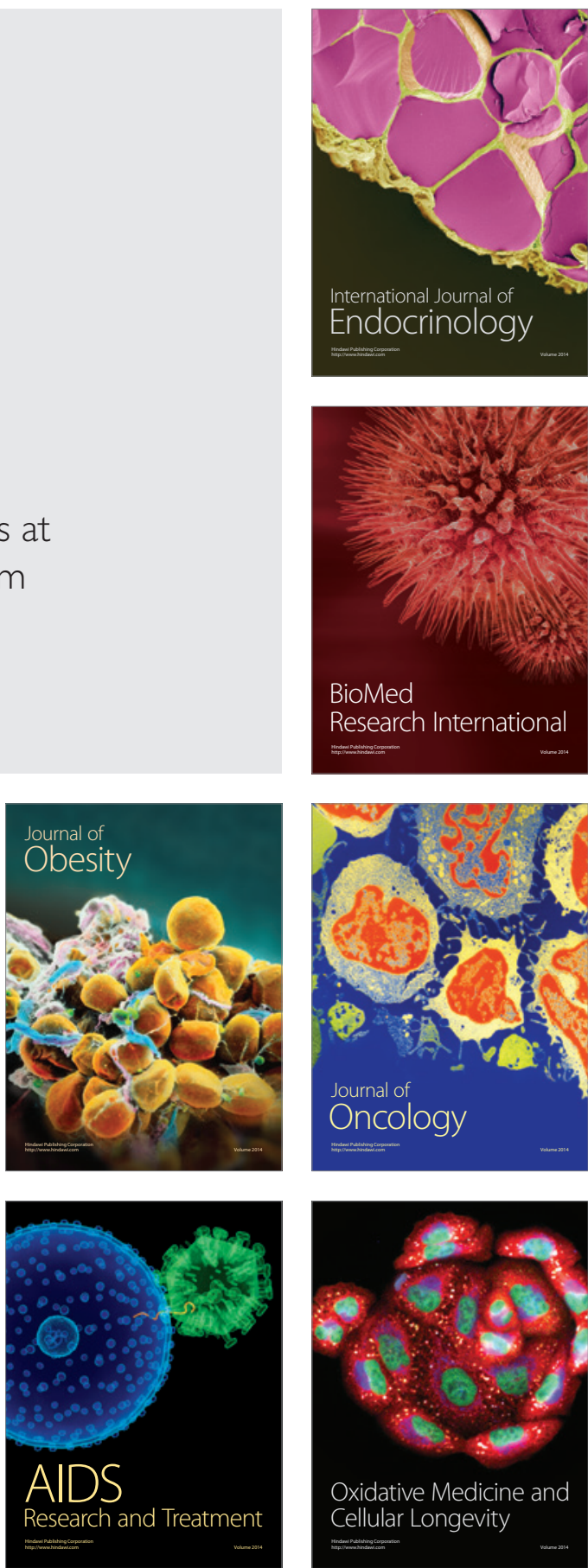